\title{
Low frequency acoustic and ultrasound waves to characterise layered media
}

\author{
${ }^{1}$ Wilkinson, P.B., ${ }^{1 *}$ Gunn, D.A., ${ }^{1}$ Holyoake, S., ${ }^{1}$ Dashwood, B., ${ }^{2}$ Brett, C.R. \& ${ }^{1}$ Rees, \\ J. \\ 1 - British Geological Survey, Environmental Science Centre, Keyworth, Nottingham, \\ NG12 5GG \\ 2 - Uniper Technologies Ltd, Ratcliffe-on-Soar, Nottingham, NG11 0EE \\ * Corresponding author: dgu@bgs.ac.uk
}

\begin{abstract}
Poor penetration and excessive absorption of high frequencies limit spectroscopic approaches using fast rise pulses for inspecting many engineered structures. So, this study focused on the alternative application of low frequency acoustic and ultrasound waves for the characterisation of challenging structures in airborne and waterborne environments. A simple, transfer matrix model approach was developed for the simulation of $1 \mathrm{D}$ sound propagation through layered media that comprise many engineered structures. This model was used to test the feasibility of using sound waves for non-destructive characterisation of an articulated lorry transported trailer and offshore foundation infrastructure. The targets were not in contact with the sound sensors and incorporated highly attenuating layers with acoustic contrasts to the surrounding medium that result in over $90 \%$ reflection of incident wave pressure. In both cases, resonances controlled by the thicknesses and interval velocities of component layers modulated sound reflection from, and transmission through the whole structure. These effects were observed as local maxima and minima in the spectra of the transmission and reflection coefficients. These spectral coefficients also determined the modulation to the temporal envelope of a linear frequency modulated pulse used to insonify the targets. In the acoustic study, which comprised only theoretical modelling, discrimination of differing cargo widths and between solid versus empty cargo trailers
\end{abstract}


was possible using the transmission coefficient. In the ultrasound study, which comprised theoretical modelling and experimental testing, discrimination of differing steel and concrete substructure thicknesses and also of gaps between them was possible using the reflection coefficient. The model outcomes indicated while an acoustic system would require around 90 to $100 \mathrm{~dB}$ of dynamic range, an ultrasound system would only require around $40 \mathrm{~dB}$ to be effective.

Keywords: Wave Propagation; Modelling; Transmission; Reflection; Spectrum

\section{Introduction:}

Many established non-destructive tests (NDT) are based upon analysis of onedimensional propagation of ultrasound waves through layered media. Ultrasound sonography involving the analysis of the arrival times and temporal characteristics of echo pulses is commonplace in materials NDT (Krautkramer \& Krautkramer 1990) and medical physics (Jensen 2006). Ultrasound spectroscopy involves additional analysis of the spectral characteristics of echoes and has traditionally used fast rise, broadband pulses of MHz frequencies or above (Clark 2004, Winkler \& Plona 1982, Jensen 2006 and Tello 2014). While ultrasound spectroscopy is widely used for material property and structural inspection, its use at high frequencies can be limited in materials with very high attenuation. Because of their greater penetration, acoustics and low frequency ultrasound $(<200 \mathrm{kHz})$ offer alternative inspection approaches in materials where higher frequencies are scattered or absorbed. But the resolution of normal sonographic approaches is limited when applied to lower frequency evaluation due to relatively long wavelengths. However, several animal studies indicated that bats and dolphins (Schmidt, 1992, Au 1993 and Au \& Simmons 2007) have discriminated thickness differences (of $0.5 \mathrm{~mm}$ ), which are beyond the limit of their spatial or temporal 
resolving capabilities $\left(1 / 20^{\text {th }}\right.$ wavelength $\& 0.7 \mu$ s for a dolphin) by detecting shifts in the echo spectra of around $3 \mathrm{kHz}$. Moreso, they appear to achieve these performance levels not with high frequency, fast-rise time pulses used in sonography, but only by generating (ultra)sound frequencies from $10 \mathrm{kHz}$ to $150 \mathrm{kHz}$ using long duration pulses, in the case of dolphins to $70 \mu$ s and bats to 25 ms (Schmidt 1992, Au 1993 and Au \& Simmons 2007).

Long duration, frequency modulated (FM) signals have been utilised successfully to extract the attenuation, velocity and thickness of non-metallic composites via spectral decomposition of echoes from single layers (Lavrentyev \& Rokhlin 1997, Raišutis et al. 2007, Humphrey et al. 2008 \& Hopper et al. 2012) and also in low frequency seismic applications (White et al. 2015). In this paper, we use a simple 1-D wave propagation model to demonstrate simple tomography or echo sensor arrangements required to extend these applications to evaluate two challenging multi-layered systems. We scope the bandwidth and potential sensitivity required of practical measuring systems, and hence establish the potential feasibility of either case. These studies include representation of each layered system by an equivalent numerical model, through which the propagation of a linear frequency modulated chirp is simulated. The dependence of notches in the frequency spectrum of the reflection coefficient, or peaks in the transmission coefficient, on key structural elements within each layered system are analysed to demonstrate how these features could be used as system condition diagnostics. The first study relates to a non-harmful, non-contact, acoustic method for screening of soft-sided, articulated cargo trailers at ferry ports. The second study relates to the evaluation of the foundation condition of offshore renewable energy infrastructure using ultrasound. Ultrasound echo spectra from equivalent laboratory 
scaled physical models are used to verify the numerical results from the second study to demonstrate the specific application to offshore foundation evaluation.

\section{Layered Media Characterisation:}

\subsection{General Principle}

Reverberation of incident sound wave energy, which penetrates a finite thickness layer and is partially transmitted and reflected at the interfaces between the layer and bounding media, is shown in Fig. 1. At a frequency where the sound wavelength is approximately twice the host layer thickness, the reflection coefficient reduces to a minimum (controlled by the losses in the materials). This first minimum is equivalent to the fundamental half-wavelength resonance (Gooberman 1968 and Krautkramer \& Krautkramer 1990) and occurs at a frequency $f_{\mathrm{r}}$ that can be estimated by the ratio of the sound velocity, $V_{\mathrm{s}}$ to thickness, $L$, of the layer, given by,

$$
f_{\mathrm{r}} \quad=\quad V_{\mathrm{s}} /(2 L)
$$

Figure 1. Reverberation of incident sound wave energy that penetrates a finite thickness layer and is partially reflected at the interfaces between the layer and bounding media; example shows a single layer bounded by water. The spectra of the reflection and transmission coefficients relate to amplitudes of the reflected and transmitted sound. Examples show notches for a fundamental frequency of 59 $\mathrm{kHz}$, such as produced by a $50 \mathrm{~mm}$ mild steel plate.

Further minima or notches appear in the reflection spectra of the echoes from single layered targets insonified with broadband, low frequency modulated signals where the reflection coefficient diminishes to local minima at frequencies where the thickness is equivalent to integer multiples of the fundamental half-wavelength resonance (Fig. 1). In the absence of attenuation, each layer has a reflection and transmission coefficient described by Gooberman (1968) as, 


$$
\begin{aligned}
& R=\frac{\left[\frac{1}{4}\left(v-\frac{1}{v}\right)^{2} \sin ^{2}\left(\frac{2 \pi L}{\lambda}\right)\right]}{\left[1+\left(\frac{1}{4}\left(v-\frac{1}{v}\right)^{2} \sin ^{2}\left(\frac{2 \pi L}{\lambda}\right)\right)\right]} \\
& T=\frac{1}{\left[1+\left(\frac{1}{4}\left(v-\frac{1}{v}\right)^{2} \sin ^{2}\left(\frac{2 \pi L}{\lambda}\right)\right)\right]}
\end{aligned}
$$

where $\pi \cong 3.142 \ldots, \lambda=$ wavelength of sound within the layer, $\lambda=\mathrm{Vs} / \mathrm{f}$, where $\mathrm{f}=$ frequency and $v=Z_{\mathrm{BL}} / Z_{0}$, the ratio of the bounded layer and bounding media acoustic impedances. Similarly, echoes backscattered from a multi-layered sequence are the result of the superposition of the incident wave that has been modulated by partial reflection and transmission, and delayed via multiple transits across the thickness of the bound layers within the sequence. Hence, it is possible that the reflection spectra of such backscattered echoes will exhibit notch characteristics associated with individual layers within the sequence. Conversely, the transmission coefficient reaches a maximum at the fundamental half-wavelength resonance and each of the associated multiples.

The energy bandwidth of the echo can be increased by extending the incident pulse width, for example to overcome losses associated with multiple partial reflection/transmission of waves reverberating within each layer. This can be achieved using a non-stationary, sinusoidal signal, where the instantaneous frequency throughout the duration of the signal is controlled by a modulating function. Both the signal duration and the modulating function are then adapted to suit the resonances and reverberant behaviour of the media under test. Widely used linear frequency modulated (LFM) signals incorporate a simple linear sweep of the instantaneous frequency 
between different frequencies at the start and end of the signal. Misaradis \& Jensen (2005) concluded that LFM signals provided up to $10 \mathrm{~dB}$ gain in signal-to-noise ratio over binary-complementary Golay coded waveforms for imaging in highly attenuating media.

\subsection{Wave Propagation in Layered Media: Numerical Model}

Redwood (1961) and Hayward et al. (1984) developed the transmission line concept to describe the operation of piezoelectric transducers, and provided general solutions to wave propagation within bounded, layered media. For an arbitrary number of layers, the transmission and reflection coefficients can be found by repeated application of these single layer calculations presented in equations $2 \& 3$. However, this recursive method is somewhat cumbersome, so a simpler, transfer matrix model was developed to explore the resonance notches of layered media associated with different applications. This approach assumes that an incident, plane pressure wave propagates in the $z$ direction, normal to the layer interfaces, and that the layers are infinite and homogeneous perpendicular to $z$. The $j$ th layer is characterised by the density $\rho_{j}\left(\mathrm{~kg} . \mathrm{m}^{-}\right.$ ${ }^{3}$ ), speed of sound $c_{j}\left(\mathrm{~m}_{\mathrm{s}} \mathrm{s}^{-1}\right)$, and attenuation coefficient $\alpha_{j}\left(\mathrm{~Np} \cdot \mathrm{m}^{-1}\right)$. Fig. 2 shows how the pressure in the $j$ th layer can be written as a superposition of incident (forward)- and reflected (backward)- propagating waves given by,

$$
p_{j}(z, t)=A_{j} e^{i\left(k_{j} z-\omega t\right)}+B_{j} e^{-i\left(k_{j} z+\omega t\right)},
$$

where $i=\sqrt{ }-1, \omega$ is the angular frequency, and the complex wavenumber is,

$$
k_{j}=\frac{\omega}{c_{j}}+i \alpha_{j}
$$

Following Mikeska \& Behrens (1976), the attenuation coefficient, $\alpha_{j}$, is assumed to be at most a quadratic function of frequency, $f$, having the form, 


$$
\alpha_{j}(f)=a_{j} f+b_{j} f^{2}
$$

where the coefficients $a_{j}\left(\mathrm{~Np} \cdot \mathrm{m}^{-1} \cdot \mathrm{Hz}^{-1}\right)$ and $b_{j}\left(\mathrm{~Np} \cdot \mathrm{m}^{-1} \cdot \mathrm{Hz}^{-2}\right)$ are either experimentally fitted (reviewed or estimated) to match the attenuation of the material forming the $j$ th layer.

Figure 2. Layout and nomenclature for the numerical process used to model the spectra of the reflection and transmission coefficients for normal incident 1D wave propagation through layered test systems.

The regions 0 and $n$ are assumed to be semi-infinite and the layers $1, \ldots, n-1$ have thicknesses $d_{1}, \ldots, d_{n-1}$ respectively. The transmission and reflection coefficients through the layered structure are calculated using a transfer matrix approach. The transfer matrix relating the pressures on the left- and right-hand interfaces of the $j$ th layer is given by,

$$
L_{j}=\left[\begin{array}{cc}
e^{-i k_{j} d_{j}} & 0 \\
0 & e^{i k_{j} d_{j}}
\end{array}\right] \text {. }
$$

Boundary conditions are applied across interfaces, including continuity of pressure and of normal particle velocity to calculate the transfer matrix between layers. Applying these at the boundary between layers $j$ and $j+1$ yields the transfer matrix across the $j$ th interface,

$$
I_{j}=\frac{1}{2}\left[\begin{array}{ll}
\left(1+\frac{\rho_{j} k_{j+1}}{\rho_{j+1} k_{j}}\right) & \left(1-\frac{\rho_{j} k_{j+1}}{\rho_{j+1} k_{j}}\right) \\
\left(1-\frac{\rho_{j} k_{j+1}}{\rho_{j+1} k_{j}}\right) & \left.\left(1+\frac{\rho_{j} k_{j+1}}{\rho_{j+1} k_{j}}\right)\right] .
\end{array}\right.
$$

The transfer matrix, $\Pi$, for the whole structure relates the amplitudes and phases of the incident, reflected and transmitted waves. It is given by the product of the transfer matrices for the individual layers and their interfaces, 


$$
\Pi=I_{0} L_{1} I_{1} L_{2} \ldots . I_{n-1} .
$$

The pressure wave in region 0 is then related to the wave in region $n$ by the expression,

$$
\left[\begin{array}{c}
A_{0} e^{i k_{0} z_{0}} \\
B_{0} e^{-i k_{0} z_{0}}
\end{array}\right]=\Pi\left[\begin{array}{c}
A_{n} e^{i k_{n} z_{n-1}} \\
B_{n} e^{-i k_{n} z_{n-1}}
\end{array}\right] .
$$

Setting the incident amplitude $A_{0}=1$, noting that $B_{n}=0$ (i.e. there is no backward propagating, incident wave in region $n$ ), and assuming that $z_{0}=0$ yields the transmission coefficient

$$
T=A_{n}^{*} A_{n}=\frac{1}{\Pi_{1,1}{ }^{*} \Pi_{1,1}}
$$

and the reflection coefficient,

$$
R=B_{0}{ }^{*} B_{0}=\frac{\Pi_{2,1}{ }^{*} \Pi_{2,1}}{\Pi_{1,1}{ }^{*} \Pi_{1,1}} .
$$

The applicability of the transfer matrix model was confirmed by Hopper et al. (2012) in the case of verified matches in modelled and experimental reflection and transmission spectra in plate-like metal and plastic targets to within $5 \mathrm{~dB}$ over frequencies from 40 $\mathrm{kHz}$ to $200 \mathrm{kHz}$.

\section{Low Frequency Acoustic Application: Cargo Screening at Ferry Ports using Acoustic Tomography}

A key goal of cargo screening at ferry ports is to detect the presence of human stowaways, and determine whether unwanted weapons, chemicals or explosives are present within canvas-sided lorry trailers. Currently, contactless cargo screening is dominated by applications of X-rays (Dinca et al. 2008), $\gamma$-ray and neutrons (Eberhardt et al. 2006), with ionizing radiation used almost exclusively for screening metal shipping containers. As an alternative to these methods, acoustic approaches present very safe methods not harmful to human life for the screening of commercial cargo trailers, where there is a higher risk of stowaways. . These were investigated to evaluate the levels of the monitored acoustic signals required such that information about the 
trailer-cargo system can be extracted. This model investigates the effects of different cargos and their arrangements on the acoustic reflection and transmission coefficients of canvas-sided trailers, where the outer covering often comprises a curtain material of 3 $7 \mathrm{~mm}$ thick vinyl-impregnated canvas. Table 1 summarises the physical properties attributed to the materials used in the model. Fig. 3 shows the basic system concept, whereby an articulated canvas-sided trailer would slowly pass between acoustic transmitting and receiving sensors.

\begin{tabular}{|c|c|c|c|}
\hline Material & Density $\left(\mathrm{kgm}^{-3}\right)$ & Speed of sound $\left(\mathrm{ms}^{-1}\right)$ & Attenuation coefficient $\left(\mathrm{Npm}^{-1} \mathrm{~Hz}^{-1}\right)$ \\
\hline Curtain & 910 & 1600 & 15 \\
\hline Wood & 750 & 4000 & 1 \\
\hline Air & 1.25 & 340 & 0.1 \\
\hline
\end{tabular}

Table 1: Physical properties of materials used in the canvas-sided cargo model. [Properties taken from Kaye \& Laby Online (http://www.kayelaby.npl.co.uk); Density: Air Section 2.1; Solid Materials - Section 2.2; Sound Velocity: Air / Solid Materials - Section 2.4; Attenuation Coefficient: Air - Section 2.1; Solid Materials - Section 2.4. N.B. Wood was modelled using the listed properties for oak and the curtain material was modelled using the listed properties for natural rubber.]

Figure 3. Trailer cargo scanner concept: Centrally positioned, variable thickness wooden crates used in modelling examples.

\subsection{Solid Wooden Cargo}

The fundamental model is based on a $3 \mathrm{~m}$ wide air-filled trailer, bounded on either side by $5 \mathrm{~mm}$ thick curtain, Figs. 3b-e. The first cargo example contrasts the reflection/transmission characteristics of a trailer carrying solid wooden crates (Fig. 3b, c) of two different widths, 150 and $550 \mathrm{~mm}$, where the cargo is centrally positioned within the trailer. Fig. 4 shows the spectral and temporal characteristics of the reflected and transmitted signals for each trailerer-cargo manifest over a 0 to $1 \mathrm{kHz}$ frequency range. General characteristics on the reflection coefficient spectra include low levels of sound energy reflected across a narrow range of frequencies from $15-40 \mathrm{~Hz}$ for both 
trailer-manifests, whereas most of the sound energy is reflected between $50-110 \mathrm{~Hz}$. [N.B. a notch equivalent to the half-wavelength resonance of the air across the whole width of the trailer would occur around $58 \mathrm{~Hz}$, but which does not appear in the spectrum because the model has essentially partitioned the trailer into smaller compartments.] Small notches in the reflection spectra occur at frequencies equivalent to the fundamental half-wavelength resonance of the front (and rear) gaps; at 123 and $143 \mathrm{~Hz}$ for the $1.425 \mathrm{~m}$ and $1.225 \mathrm{~m}$ gaps respectively (labelled on Figs. 4a, b). The fundamental occurs at slightly greater frequencies than predicted via simple application of Eqs. 1 and 2 of 119 and $138 \mathrm{~Hz}$ respectively, which strictly only apply to lossless materials. However, the frequencies predicted by Eq. 1 and 2 are approximations to the spectral intervals between the successive notch locations of the higher frequency resonance harmonics. A linear increase in attenuation with frequency contributes to the decreasing notch-depths with increasing harmonic order. The notch successions on each reflection spectra are twinned with peak successions on the equivalent transmission spectra, marking local transmitted maxima about multiple frequencies associated with resonance harmonics in the front and rear air gaps.

Figure 4. Trailers with solid wooden crate cargos - centrally positioned: Temporal and spectral characteristics of the transmitted/received signals.

The transmission and reflection spectral functions serve to filter the temporal sound signals propagating through the trailer. Fig. 4 shows the example of an LFM signal with start/end frequencies of $0 \mathrm{~Hz} / 300 \mathrm{~Hz}$ transmitted over a 1 second duration and amplitude modulated with a Hann window. Fig. 4 also shows the reflected and transmitted signals resulting from using this signal to interrogate each trailer-cargo manifest. Resonant transmission through the trailer causes greater amplitudes over 
narrow frequency ranges in the transmitted signal, e.g. at around 22, 123, and $238 \mathrm{~Hz}$ for a $150 \mathrm{~mm}$ wide crate, and 23, 143, and $277 \mathrm{~Hz}$ for a $550 \mathrm{~mm}$ crate. The local peak amplitudes between $0.05-0.15 \mathrm{~s}, 0.35-0.50 \mathrm{~s}$, and $0.75-0.85 \mathrm{~s}$ on the transmitted time domain signal (through the $150 \mathrm{~mm}$ crate) relate to the first, second, and third peaks on the transmission spectrum respectively. Transmissivity of frequencies around $22 \mathrm{~Hz}$ is approximately $-20 \mathrm{~dB}$, whereas it is $-40 \mathrm{~dB}$ at frequencies around $122 \mathrm{~Hz}$, and $-60 \mathrm{~dB}$ around $237 \mathrm{~Hz}$. Thus, the ratios of the amplitudes of the transmitted to the incident signal are about $0.1,0.01$, and 0.001 respectively at the three local peaks, meaning that the trailer is around 10 times less transmissive at $123 \mathrm{~Hz}$ than at $22 \mathrm{~Hz}$, and 100 times less transmissive at $238 \mathrm{~Hz}$ than at $22 \mathrm{~Hz}$.

\subsection{Empty Wooden Cargo}

This second example uses empty cargo crates in the same trailer model as above, providing potential cavities for contraband items or stowaways (that, unlike the gaps in the trailer are hidden from view). This example contrasts the reflection/transmission characteristics of trailers carrying centrally positioned, empty wooden crates (Fig. 5) with internal widths of 100 and $500 \mathrm{~mm}$, and the same external dimensions as the solid examples. Notches in the spectra of the reflection coefficient related to half-wavelength resonance of the front (and rear) gaps are at 125 and $144 \mathrm{~Hz}$ (a shift up-frequency of 2-4 $\mathrm{Hz}$ as the gaps have narrowed to $1.425 \mathrm{~m}$ and $1.225 \mathrm{~m}$ gaps respectively by comparison with the solid crate). There is greater transmission of low frequency $(<25 \mathrm{~Hz})$ energy through the trailers with the empty crates compared to the solid crates. On the empty $150 \mathrm{~mm}$ transmission spectrum, a minor local maxima in the spectrum at around $60 \mathrm{~Hz}$ leads to the local maximum in the temporal envelope at around 0.25 seconds (i.e. in addition to a larger peak between 0.05-0.15 that still exists around $23 \mathrm{~Hz}$, and which is 
of $10 \mathrm{~dB}$ greater amplitude than in the $150 \mathrm{~mm}$ solid see Fig. 5a). The local transmission maxima around $144 \mathrm{~Hz}$ (front gap resonance) is the cause of the peak in the temporal envelope at $0.45 \mathrm{~s}$. In comparison with transmission spectra from the solid cargo, the peaks related to the multiple harmonic resonances in the front (and rear) air gaps, e.g. at $241 \mathrm{~Hz}(150 \mathrm{~mm})$ and $279 \mathrm{~Hz}(550 \mathrm{~mm})$ all occur at lower strengths (i.e. around $-10 \mathrm{~dB}$ more loss), leading to an apparent absence of frequencies above $180 \mathrm{~Hz}$ in the temporal signals through the empty crates after 0.6 seconds. For example, unlike the $150 \mathrm{~mm}$ solid cargo, there appears to be no energy between $0.75-0.85$ seconds on the transmitted signal through the $150 \mathrm{~mm}$ wide empty cargo (c.f. transmission spectra of Fig. 4a with 5a).

Figure 5. Trailers with empty wooden crates - centrally positioned:

Temporal and spectral characteristics of the transmitted/received signals.

There is a minor local maximum around $23 \mathrm{~Hz}$ on the transmission spectrum of the trailer carrying the crate with the larger gap $(550 \mathrm{~mm})$, but the coefficient decreases sharply at higher frequencies. This leads to high transmittance of frequencies $<23 \mathrm{~Hz}$ and results in the local maximum in the temporal envelope at around $0.075-0.1$ seconds (see Fig. 5b), but with much smaller amplitudes after 0.2 seconds (i.e. at frequencies above $60 \mathrm{~Hz}$ ). The very small peak in the temporal envelope around $0.5 \mathrm{~s}$ is caused by resonance in the front (rear) air gaps around $144 \mathrm{~Hz}$. Fundamental resonance of the air gap inside the crate occurs at $340 \mathrm{~Hz}$; this peak can be distinguished in the transmission spectrum (Fig. 5b) between the second and third multiples of the front (and rear) gap resonance. The second harmonic of the crate air gap resonance (at $680 \mathrm{~Hz}$ ) superposes onto the fifth harmonic of the front gap resonance, leading to slightly higher transmittance about this narrow range of frequencies. 
This first study comprised theoretical modelling only, but did indicate that it is feasible to distinguish solid from empty cargo and diagnose the cavity dimensions from the spectral characteristics of acoustic signals leaking from the cargo-trailer. Further proof of concept would benefit from additional experimental evidence, which could, for example, build on similar work by Hutchins et al. (2010), who presented measurements from laboratory mock ups of near full-scale canvas-sided cargo-trailers. While Hutchins et al. (2010) did not test realistic cargo crates, by retransmitting time reversed tomographic signals they were able to identify clear resonance peaks associated with the compartments within the laboratory mock up.

\section{Low Frequency Ultrasound Application: Offshore Wind Turbine Foundations}

The life-span of offshore wind turbines and their performance (and hence windfarm capacity) are critically dependent upon the condition of key components including the foundation. The wind turbine foundation is subject to harsh strain-cycling due to environmental stresses from variable winds and large tidal ranges (Iliopoulos et al. 2016). The subsea location of the foundation, shown in Fig. 6, offers a potential environment for in situ ultrasound inspection methods, accessible either externally or even internally. The schematic in Fig. $6 \mathrm{~b}$ shows the foundation structure to comprise two mild steel substructures including a $4.3 \mathrm{~m}$ internal diameter (ID), $50 \mathrm{~mm}$ thick cylindrical monopile which is driven into the seabed, over which a $4.54 \mathrm{~m} \mathrm{ID,} 50 \mathrm{~mm}$ thick cylindrical transition piece is supported by a $70 \mathrm{~mm}$ thick annulus of concrete grout (specially formulated for subsea pumping). The grout is subjected to large, complex stresses leading to progressive deterioration in the foundation condition manifest in a range of defects such as debonding and the growth of gaps at its interfaces 
with the steel sub-structures, or even a complete loss of grout in parts of the annulus (Brett et al. 2018).

Figure 6. Schematic showing the structural elements and overall dimensions of offshore monopile wind turbine foundations.

The capabilities of several NDT techniques to discriminate the foundation structure and condition have been evaluated by the wind energy community. Methods based on gamma radiography, impulse-response testing, guided waves, pulse-echo and array ultrasonic testing have been trialled (Brett et al. 2018). Methods requiring two-sided access across the structure were considered impractical due to uncertainties in coupled sensor positioning and alignment. Using ultrasound at $\mathrm{MHz}$ frequencies, insufficient echo amplitudes could be gathered to indicate the condition of even the nearest steelgrout interface, and this method could not satisfactorily differentiate water filled gaps from fully bonded grout (Brett et al. 2018). The very large contrast in acoustic impedance (and other physical properties) between the water (environment) and the front steel sub-structure limits the penetration into the foundation making inspection extremely challenging. Also, testing at high frequencies up to $1 \mathrm{MHz}$, including tests on grout core samples by Iliopoulos et al. (2016) at what appear around $500 \mathrm{kHz}$ indicated attenuations of around $1 \mathrm{~dB} / \mathrm{mm}(115 \mathrm{~Np} / \mathrm{m})$ through the grout material, which is prohibitively high to enable detection of echoes from the furthest steel-grout interface. Hence, a modelling exercise to scope the propagation of low frequency ultrasound was proposed.

\subsection{Offshore Wind Turbine Model: Grout Thickness}

While positive proof of concept could only be satisfied with experimental evidence, the acoustic transfer model was applied to scope the sensitivity of the reflectivity of the 
structure to variable foundation conditions. Sensitivities to grout thickness, and to gaps of various apertures located either at the front or the rear steel-grout interfaces were investigated. Fig. 7a shows the physical properties and dimensions used in a halfthickness scale model, which was chosen to prove the physical principles of the approach, while enabling verification using smaller, and hence far lighter samples in subsequent experimental testing (i.e. $35 \mathrm{~kg}$ for half-thickness scale instead of $80 \mathrm{~kg}$ for a full-thickness sample). Table 2 summarises the frequency locations of the resonance notches that would occur in a single steel or grout layer in the model. Fig. $7 \mathrm{~b}$ shows successive reflection spectra from foundation systems with central grout thicknesses ranging from 20.5 to $37 \mathrm{~mm}$. Note that a sequence of relatively low frequency notches relates to half-wavelength resonance in the grout layer, from $63 \mathrm{kHz}$ in the $37 \mathrm{~mm}$ grout to $115 \mathrm{kHz}$ in the $20.5 \mathrm{~mm}$ grout. Note also that the notches deepen as their frequencies approach what appears to be the resonance frequency in the front steel layer, which was modelled to be $118 \mathrm{kHz}$ in a single steel plate. Generally, as the frequency difference between the fundamental resonances in the front steel and the central grout reduces, the depth of the notch closest to the modelled steel resonance frequency increases, hence deepest notch occurs on the $20.5 \mathrm{~mm}$ thick spectrum. (This is another example of the superposition of multiple reverberances, similar to the above cargo example.)

Figure 7. Reflection spectra for half-thickness scale model of wind turbine monopile foundation structure.

\begin{tabular}{|c|c|c|c|c|}
\hline \multicolumn{5}{|l|}{ Single Plate } \\
\hline \multirow[t]{2}{*}{ Resonance } & \multirow{2}{*}{$\begin{array}{l}\text { Experimental } \\
\text { Frequency }\end{array}$} & \multicolumn{3}{|c|}{ Model Parameters } \\
\hline & & Frequency & Velocity & Attenuation \\
\hline $\begin{array}{l}\text { Steel Plate (25.2 } \\
\mathrm{mm})\end{array}$ & $115 \mathrm{kHz}$ & $118 \mathrm{kHz}$ & $5918 \mathrm{~m} \cdot \mathrm{s}^{-1}$ & $0 \mathrm{~Np} . \mathrm{m}^{-1}$ \\
\hline Grout $(37.47 \mathrm{~mm})$ & $62 \mathrm{kHz}$ & $63 \mathrm{kHz}$ & $4700 \mathrm{~m} \cdot \mathrm{s}^{-1}$ & 10 Np.m ${ }^{-1}$ \\
\hline
\end{tabular}




\begin{tabular}{|c|c|c|c|c|}
\hline \multirow{2}{*}{ Gap Aperture } & \multicolumn{2}{|c|}{ Gap at Front Interface } & \multicolumn{2}{|c|}{ Gap at Rear Interface } \\
\hline & Experimental & Model & Experimental & Model \\
\hline Bonded No Gaps & $\begin{array}{c}\text { Lower- } 108 \\
\text { kHz }\end{array}$ & $\begin{array}{c}\text { Lower- } 105 \\
\text { kHz }\end{array}$ & $\begin{array}{c}\text { Upper- } 119 \\
\text { kHz }\end{array}$ & $\begin{array}{c}\text { Upper- } 120 \\
\text { kHz }\end{array}$ \\
\hline $0.5 \mathrm{~mm}$ & $116 \mathrm{kHz}$ & $120.3 \mathrm{kHz}$ & $126 \mathrm{kHz}$ & $126.8 \mathrm{kHz}$ \\
\hline $1.0 \mathrm{~mm}$ & $115 \mathrm{kHz}$ & $119.9 \mathrm{kHz}$ & $124 \mathrm{kHz}$ & $123.6 \mathrm{kHz}$ \\
\hline $1.5 \mathrm{~mm}$ & $115 \mathrm{kHz}$ & $119.4 \mathrm{kHz}$ & $123 \mathrm{kHz}$ & $122.4 \mathrm{kHz}$ \\
\hline
\end{tabular}

Table 2. Frequency locations of lowest local notch minima for modelled and experimental spectra of half-scale foundation structures including gap defects.

[The steel and grout velocities were measured on single panels of each material. The values for attenuation were estimates based upon property values indicated by Kaye \& Laby Online (http://www.kayelaby.npl.co.uk for similar materials.]

\subsection{Offshore Wind Turbine Model: Gap Defects}

A physical sample was prepared by moulding grout onto a $25 \mathrm{~mm}$ thick mild steel plate.

The original grout was moulded to a thickness of around $45 \mathrm{~mm}$ and then ground flat and parallel to the steel mould surface at a nominal grout thickness of $37.47 \mathrm{~mm}$ (where the parallelism was measured to within 75 micron). A second mild steel plate was clamped against the surface ground face of the grout. (Both steel plates were flat/parallel to within 50 microns). The experimental echo set-up include a wideband ultrasound sensor with a nominal centre frequency of $96 \mathrm{kHz}$ positioned $475 \mathrm{~mm}$ from the target and used to insonify the steel faces with sound waves produced by a frequency modulated chirp ranging from $20 \mathrm{kHz}$ to $200 \mathrm{kHz}$. The external face of the clamped steel (free plate) was insonified for gap testing at the front steel-grout interface, and the face of the fixed, moulded steel plate insonified for respective rear gap testing, using this experimental set-up shown in the photograph of Fig. 8. The beam generated by the transducer spread in the far field between $+/-5$ to $+/-12$ degrees and any curvature of the target surface away from the transducer (convex) will reinforce spreading of the ultrasound beam and result in lower amplitude echoes from the target, whereas concave curvature towards the transducer will counteract the beam spreading 
and lead to higher amplitude echoes. Resonance of non-normally incident raypaths within the steel will also reduce the Q-factor of the spectral notch, but these effects were considered negligible given such low beam angles (circa $5^{\circ}$ ) and this transducer offset.

Figure 8. Experimental set-up showing the ultrasound transmitter-receiver (1) and the steel-concrete-steel-sample (2), which is clamped to maintain contact between the concrete and the free steel plate.

Insonification of the moulded steel plate with heavy clamping applied to the sample was considered to be representative of a fully bonded foundation structure, where Fig. 9a compares the experimental to the modelled reflection spectrum that has been convolved with the transducer transmit-receive sensitivity function. Loosening of the clamping force (to a point where the clamps just support their submerged own weight) results in a relaxation of the acoustic loading between the grout and free steel plate (on the far side of the grout). Changes in the notch characteristics from the good to relaxed conditions appear consistent with the development of debonding or very small aperture gapping of the interface on the far side of the grout (see graph labelled 'Rear De-BondedExperimental (S9-G8-S8)' in Fig. 9a). This is likely to be due to a reduction with clamping relaxation of the contact area between the grout and far steel interface. The experimental spectrum exhibits notches at 108 and $119 \mathrm{kHz}$, compared to notches at 105 and $120 \mathrm{kHz}$ on modelled spectrum (with $37 \mathrm{~mm}$ grout in Fig. 9a). The differences are attributed to differences between the real physical properties and those used in the model, the deviation of the physical sample from perfectly bonded, and also, inhomogeneity in the grout (and hence its deviation from a bulk continuous medium). The dimensions and the resonant frequencies of the single steel and grout plates were also measured as part of the test programme and found to be: Steel $25.2 \mathrm{~mm}$ with a resonance of $115 \mathrm{kHz}$; grout $37.47 \mathrm{~mm}$ with a resonance of $62 \mathrm{kHz}$. 
Small shims, comprising metal foil or strips of varying thickness were inserted between the free steel plate and the grout by way of introducing gaps of controlled apertures at the free interface. The above insonification protocol was repeated to gather a series of reflection spectra from half-thickness scale foundation models exhibiting a range of front and rear gap defects. The modelled and experimental spectra for gaps of $0.5,1.0$ and $1.5 \mathrm{~mm}$ apertures located at the front steel-grout interface are compared in Fig. 9b, and for gaps located at rear interface in Fig. 9c. (N.B. the experimental and modelled spectra have sampling intervals of $1 \mathrm{kHz}$ and $0.1 \mathrm{kHz}$ respectively). Table 2 summarises the smallest local notch minimum, which occurs at successively lower frequencies with increasing gap apertures, in all spectra (experimental and modelled). Deeper notches are more readily distinguished on the spectra for gaps located at the front interface, whereas, shallower notches are associated with gaps at the rear interface. In the case of the front gaps, the $1.0 \mathrm{~mm}$ gap produces the deepest notches at 115 and $120 \mathrm{kHz}$ on the experimental and modelled spectra. Although the frequency locations of the notches differ on experimental and modelled spectra (c.f. Table 2), both cases go through the same growth and decline cycle that appears to occur about the resonance of the front steel plate. In the case of the rear gaps, there is a better match between the experimental and modelled responses. Note again, the growth in depth as the notch locations approach the frequency of resonance in the steel. Note also, for this relatively narrow frequency range, the model used frequency independent estimates of attenuation in the steel and the grout. Further testing will result in greater refinement of these values and greater understanding of their dependence on frequency. Other minor mismatches between the modelled and experimental spectra are attributed to: i. differences in the 
physical parameters of the model and sample (see Table 2), and ii. a deviation of the sample set-up from the numerical model configuration, including non-continuous acoustic loading between the grout and the free steel at the clamped interface and inhomogeneity of the grout matrix. However, the common signature features on the modelled and experimental spectra indicate that a low frequency echo ultrasound method for foundation condition evaluation is highly feasible.

Figure 9. Experimental and modelled reflection spectra for half-thickness scale wind turbine foundations with structural defects; front/rear steel $25 \mathrm{~mm}$, central grout 37 $\mathrm{mm}$ thick. Model parameters: Steel $5918 \mathrm{~m} / \mathrm{s}, 0 \mathrm{~Np} / \mathrm{m}$; Grout 4700 m/s, 10 Np/m (frequency independent).

\section{Discussion and conclusions}

Use of sound to inspect targets with a very high acoustic contrast to their surrounding medium is challenged by poor penetration into the area requiring inspection. Excessive attenuation at high frequencies further inhibits penetration into the target, making standard ultrasound sonography unsuitable in these cases, due to poor sensitivity. Use of low frequency sound overcomes many of the problems of penetration but requires analysis in the spectral domain in order to understand the structure of layered media. In this study, 1D sound wave propagation through layered structures representing two challenging applications was tested using a transfer matrix model. Local minima on the spectrum of the reflection coefficient and local maxima on the spectrum of the transmission coefficient occur at the frequencies associated with half-wavelength resonance within individual layers comprising these complex structures. These effects modulate the temporal envelope of the signals that are reflected from and transmitted through the composite layered system. 
In the first case study relating to the inspection of a lorry transported cargo trailer, minima (and maxima) at the lowest or fundamental frequency are related to the dimensions of the compartments within the trailer and cargo cavities, and the acoustic propagation velocity of medium within them. Thus, where velocity is known (e.g. sound velocity in air is approx. $340 \mathrm{~m} \cdot \mathrm{s}^{-1}$ ), it is feasible to distinguish solid from empty cargo and diagnose the cavity dimensions from the spectral characteristics of acoustic signals leaking from the cargo-trailer. Information relating to cavity resonance is contained within both the reflected and transmitted signals. However, a methodology for assaying and classifying the trailer cargo is unlikely to rely upon the reflection spectrum or temporal echo. While most of the incident energy is reflected, given sufficient dynamic range, the potential exists to extract more information about the structure from the signal that has been transmitted through the cargo. Certainly, there appear to be contrasts between the transmission spectra and the transmitted temporal signals to distinguish between narrow versus wide crates, and solid versus empty crates. While the transmitted temporal signals appear very different, these differences are largely due to low frequency interference, but where much of the information relating to cargo layering structure is actually carried in the higher frequency energy. Hence, a scanner receiver with very high dynamic range would still be required to capture the information that is contained within the modulation of the higher frequencies. The bandwidth of a suitable detection system would have to be of the order of $1 \mathrm{kHz}$, if for example higher order harmonics of internal crate resonance are to be captured. Thereafter, the viability of this method lies in sufficient dynamic range and resolving capability of the receiving system. The relative intensity of the second harmonic of the crate air gap resonance at $680 \mathrm{~Hz}$ is around $-90 \mathrm{~dB}$. To resolve this peak, a linear 
scanning system would have to be capable of resolving $30 \mu \mathrm{Pa}$ for every $1 \mathrm{~Pa}$ of incident sound pressure (and the noise floor would probably need to be a further -15 dB). Alternatively in this case, direct coupling and use of the vinyl side wall as an acoustic diaphragm (similar to coupling medical ultrasound into the body) may eliminate incident reflection and provide a means of increasing the relative amplitudes of the transmitted signals.

In the case of the second study of a monopile wind turbine foundation, a tomographic approach is largely impracticable due to difficulties in aligning sensors inside and outside of the structure. The subsea location of the foundation structure makes it well situated for echo-reflection based non-destructive ultrasound inspection. Scattering of ultrasound from mussel shell colonies on the external surface of the transition piece within the inter-tidal range, further favours access and incidence from the internal surface of the monopile. The characteristic reflection responses of the half-thickness scale foundation model and experimental spectra compare very well. Indeed, these results verify that both the physical principle and sensitivity of the reflection-ultrasound technique make it highly suited to offshore monopile foundation inspections. The presence of closely spaced dual notches about the front steel resonance makes the method highly suitable for distinguishing foundations in good condition from those with gap defects. Also, single notch characteristics over different frequency bands further enables distinction between gap defects either at the front or the rear steel-grout interfaces. Noting that this study was at half linear scale, thus in situ inspection frequency ranges could be commensurately half scaled, hence a field scanner receiver would require a bandwidth of circa $100 \mathrm{kHz}$. The receiver would only require a dynamic range around $30-40 \mathrm{~dB}$, which can be readily accommodated by most 
standard amplifier systems in conjunction with existing piezoelectric transducers. A field system with a spectral resolution of the order of hundreds of $\mathrm{Hz}$ would be recommended, requiring relatively long field records that would then challenge the in situ inspection configuration, such as in terms of sensor offset and the inspection spot size on the target. However, the strong positive proof of concept from our early experiments has provided very compelling evidence for follow-up testing and development of a field ready system, e.g. to Technology Readiness Level (TRL) 5 or 6.

In conclusion, a 1D wave propagation model was developed and applied to test the feasibility of non-contact, structural condition evaluation using air-borne acoustic and water-borne, low frequency ultrasound waves. The acoustic study focused on inspection of a trailer-cargo manifest, and the ultrasound study on the condition of offshore wind turbine foundations. The modelling outcomes indicated that very high dynamic range would be required for an acoustic system for trailer-cargo inspections, making the realisation of a practical system quite challenging. However, a water-borne wind turbine foundation inspection system, requiring a much smaller dynamic range, would be readily realised using existing components.

\section{Acknowledgements}

The numerical wave propagation model was developed as part of the EPSRC funded Biologically Inspired Acoustic Systems project (EP/C523776/1). The research and findings relating to the lorry transported cargo trailer were supported by the EPRSC funded Acoustic Tomography and Standing Wave Resonance (EP/G004102/1) project. The research and findings relating to monopile wind turbine foundations were supported by the NERC funded Wind Turbine Foundation Ultrasonic Spectral Characterisation 
project (NE/M008444/1) and the E.On New Build and Technology Ltd. contract 4500070630/817/2122. The contributions of Wilkinson, Gunn, Dashwood, Holyoake and Rees are published with the permission of the Executive Director of the British Geological Survey. 


\section{References}

1. Krautkramer, J \& Krautkramer, H. Ultrasonic Testing of Materials. $4^{\text {th }}$ Ed. Springer Verlag, November 1990: 677p. ISBN: 0387512314.

2. Jensen, JA. Medical ultrasound imaging. Progress in Biophys. \& Molecular Biol. 2006;93:153-165.

3. Clark, R. Rail flaw detection: overview and needs for future developments. $N D T \& E$ Int. 2004;37:111-118.

4. Winkler, KW \& Plona, TJ. Technique for measuring ultrasonic velocity and attenuation spectra in rocks under pressure. J. Geophys. Res. 1982;87 B13:1077610780.

5. Tello, LN, Azuaje, DC \& Tran, D. High Resolution Real-Time Thickness Measurement of Internal and External Casing Anomalies with Ultrasonic Scanner Tools. SPE Int. Oilfield Corrosion Conf. \& Exhib. 2014, 12-13 May, Aberdeen, Scotland.

6. S. Schmidt. Perception of structured phantom targets in the echolocating bat, Megaderma lyra. J. Ac. Soc Am. 1992; 91(No.4/1):2203-23.

7. W.W. L. Au (1993). Sonar of Dolpins. Springer, 1993, 292p.

8. Au, WWL \& Simmons, JA. Echolocation in dolphins and bats. Physics Today. 2007;60 (9):40-45.

9. Lavrentyev, AI \& Rokhlin, SI. Determination of elastic moduli, density, attenuation, and thickness of a layer using ultrasonic spectroscopy at two angles. J. Ac. Soc. Am. 1997;102 (6):3467-3477.

10. Raišutis, R, Kažys, R \& Mažeika, L. Application of the ultrasonic characterization methods for highly attenuating plastic materials. NDT and E Int. 2007;40 (4):324-332.

11. Humphrey, VF, Robinson, SP, Smith, JD, Martin, MJ, Beamiss, GA, Hayman G \& Carroll, NL. Acoustic characterization of panel materials under simulated ocean conditions using a parametric array source. J. Ac. Soc. Am. 2008;124, (2): 803-814.

12. Hopper, C, Assous, S, Gunn, DA, Jackson, PD, Wilkinson, PB, Rees, JG, O'Leary, RL\& Lovell, MA. Bio-inspired low frequency material characterisation. Advances in Acoustics and Vibration. Research Article 927903. 2012:1-12.

13. White, JC, Williams, GA, Grude, S \& Chadwick, RA. Utilizing spectral decomposition to determine the distribution of injected $\mathrm{CO} 2$ at the Snøhvit Field. Geophysical Prospecting, 2015;63 (5):1213-1223.

14. Gooberman, GL. Ultrasonics Theory and Application. The English Universities Press, 1968; London.

15. Misaridis, $\mathrm{T} \&$ Jensen, JA. Use of modulated excitation signals in medical ultrasound. Part II. Design and performance for medical imaging applications. IEEE Trans. Ultrasonics, Ferroelec. \& Freq. Control. 2005;52 (2):192-207.

16. Redwood, M. Transient performance of a piezoelectric transducer. J. Ac. Soc. Am. 1961;33 (4):527-536.

17. Hayward, G, Macleod, CJ \& Durrani, TS. A systems model of the thickness mode piezoelectrica transducer. J. Ac. Soc. Am. 1984: 76 (2):369-382.

18. Mikeska, EE \& Behrens, JA. Evaluation of transducer window materials. J. Ac. Soc. Am. 1976;59 (6):1294-1298.

19. Dinca, D, Schubert, JR \& Callerame, J. X-ray backscatter imaging. Proc. SPIE. 2008; Vol. 6945:Paper 6945-16.

20. Eberhardt, JE, Rainey, S, Stevens, RJ, Sowerby, BD \& Tickner, JR. Fast Neutron and Gamma-Ray Interrogation of Air Cargo Containers. International Workshop on Fast 
Neutron Detectors, 2006, April 3 - 6, University of Cape Town, South Africa Paper 092.

21. Hutchins, D, Davis, L, Assous, S, Hopper, C, Wilkinson, PB, Jackson, P, Gunn, D \& Zimmerman, P. Optimum signals for acoustic cargo security screening. Proc. $20^{\text {th }}$ Int. Congress on Acoustics. 2010, 23-27 Aug, 2010, Sydney, Australia.

22. Iliopoulos, AN, Van Hemelrijck. D, Vlassenbroeck, J \& Aggelis, DG. Assessment of grouted samples from monopile wind turbine foundation using combined nondestructive techniques. Const. \& Build. Mat., 2016, V122, 855-862

23. Brett, CR, Gunn, DA, Dashwood, BAJ, Holyoake, SJ \& Wilkinson, PB. (2018). The inspection of foundations in offshore wind turbines. Insight - the Journal of the British Institute of NDT. Vol 60, No. 1, 19-27, Jan 2018. 


\section{Figure Captions:}

Figure 1. Reverberation of incident sound wave energy that penetrates a finite thickness layer and is partially reflected at the interfaces between the layer and bounding media; example shows a single layer bounded by water. The spectra of the reflection and transmission coefficients relate to amplitudes of the reflected and transmitted sound. Examples show notches for a fundamental frequency of $59 \mathrm{kHz}$, such as produced by a $50 \mathrm{~mm}$ mild steel plate.

Figure 2. Layout and nomenclature for the numerical process used to model the spectra of the reflection and transmission coefficients for normal incident 1D wave propagation through layered test systems.

Figure 3. Trailer cargo scanner concept:

Centrally positioned, variable thickness wooden crates used in modelling examples.
a. Concept based on a linear acoustic tomography system.
b. Cargo A: $150 \mathrm{~mm}$ solid wooden crate.
c. Cargo B: $550 \mathrm{~mm}$ solid wooden crate.
d. Cargo C: $150 \mathrm{~mm}$ empty wooden crate.
e. Cargo B: $550 \mathrm{~mm}$ empty wooden crate.

Figure 4. Trailers with solid wooden crates - centrally positioned: Temporal and spectral characteristics of the transmitted/received signals.

a. Cargo A: $150 \mathrm{~mm}$ solid wooden crate.

b. Cargo B: $550 \mathrm{~mm}$ solid wooden crate.

Figure 5. Trailers with empty wooden crates - centrally positioned: Temporal and spectral characteristics of the transmitted/received signals.
a. Cargo C: $150 \mathrm{~mm}$ empty wooden crate.
b. Cargo D: $550 \mathrm{~mm}$ empty wooden crate.

Figure 6. Schematic showing the structural elements and overall dimensions of offshore monopile wind turbine foundations.
a. Transition piece (yellow) at base of wind turbine.
b. Foundation detail for monopile wind turbine.

Figure 7. Reflection spectra for half-thickness scale model of wind turbine monopile foundation structure.
a. Nominal model dimensions, properties and wave propagation modes. Outer layers (dark grey): mild steel $25 \mathrm{~mm}, 5918 \mathrm{~m} / \mathrm{s}, 0 \mathrm{~Np} / \mathrm{m}$; Centre (light grey): grout $37 \mathrm{~mm}, 4700 \mathrm{~m} / \mathrm{s}, 10 \mathrm{~Np} / \mathrm{m}$.
b. Effect of grout thickness on model outcomes: Reflection spectra for 20.5 - $37 \mathrm{~mm}$ thick grout. Y-Axis: Reflection Coefficient; X-Axis: Frequency (MHz)


Figure 8. Experimental set-up showing the ultrasound transmitter-receiver (1) and the steel-concrete-steel-sample (2), which is clamped to maintain contact between the concrete and the free steel plate.

Figure 9. Experimental and modelled reflection spectra for half-thickness scale wind turbine foundations with structural defects; front/rear steel $25 \mathrm{~mm}$, central grout 37 $\mathrm{mm}$ thick. Model parameters: Steel $5918 \mathrm{~m} / \mathrm{s}, 0 \mathrm{~Np} / \mathrm{m}$; Grout $4700 \mathrm{~m} / \mathrm{s}, 10 \mathrm{~Np} / \mathrm{m}$ (frequency independent).

a. Fully bonded steel-grout-steel structure. Blue solid: Experimental: notches at $108 \mathrm{kHz}$ and $119 \mathrm{kHz}$. Grey Solid: Very loose clamping, effectively relaxing the acoustic loading of the rear steel-grout interface. Red dash: Modelled: notches at $105 \mathrm{kHz}$ and $120 \mathrm{kHz}$ superimposed onto transducer sensitivity function. Y-axis: A.U.; X-axis - MHz.

b. Gaps at front steel-grout interface. Solid - Experimental: Gap apertures of $0.5 \mathrm{~mm}$-notch at $116 \mathrm{kHz} ; 1.0 \mathrm{~mm}-115 \mathrm{kHz} ; 1.5 \mathrm{~mm}-115 \mathrm{kHz}$. Dashed Models: Gaps of $0.5 \mathrm{~mm}$-notch at $120.3 \mathrm{kHz} ; 1.0 \mathrm{~mm}-119.9 \mathrm{kHz} ; 1.5 \mathrm{~mm}-$ 119.4 kHz. Y-axis: A.U.; X-axis - MHz.

c. Gaps at rear steel-grout interface. Solid - Experimental: Gaps $0.5 \mathrm{~mm}$-notch at $126 \mathrm{kHz} ; 1.0 \mathrm{~mm}-124 \mathrm{kHz} ; 1.5 \mathrm{~mm}-123 \mathrm{kHz}$. Dashed - Models: Gaps of $0.5 \mathrm{~mm}$-notches $119.5 / 126.8 \mathrm{kHz} ; 1.0 \mathrm{~mm}-119.1 / 123.6 \mathrm{kHz} ; 1.5 \mathrm{~mm}$ 118.9/122.4 kHz. Y-axis: A.U.; X-axis - MHz.

\section{Figures:}



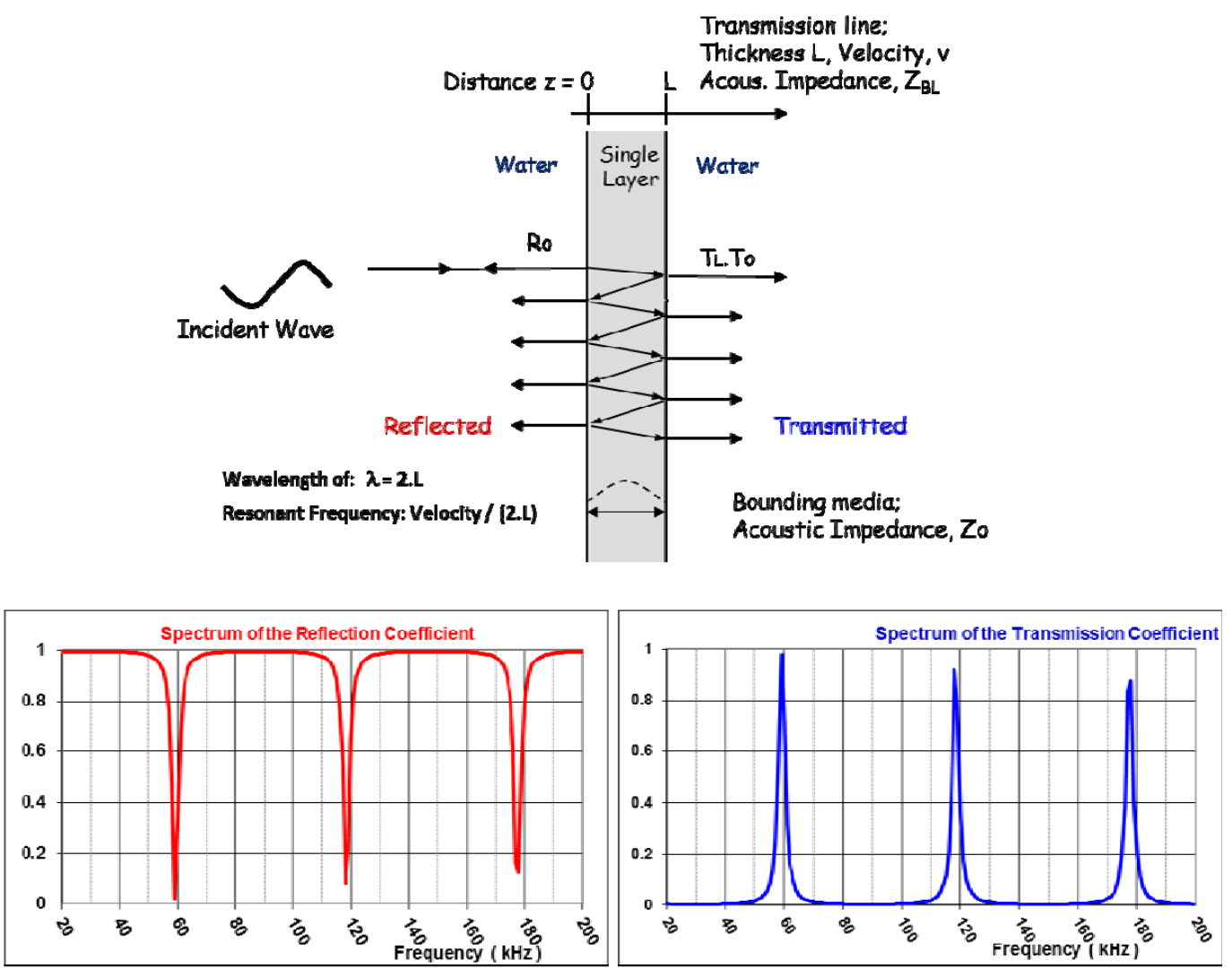

Figure 1. Reverberation of incident sound wave energy that penetrates a finite thickness layer and is partially reflected at the interfaces between the laver and bounding media; example shows a single layer bounded by water. The spectra of the reflectlon and transmission coefficlents relate to amplitudes of the reflected and transmitted sound. Examples show notches for a fundamental frequency of $59 \mathrm{kHz}$, such as produced by a $50 \mathrm{~mm}$ mild steel plate. 


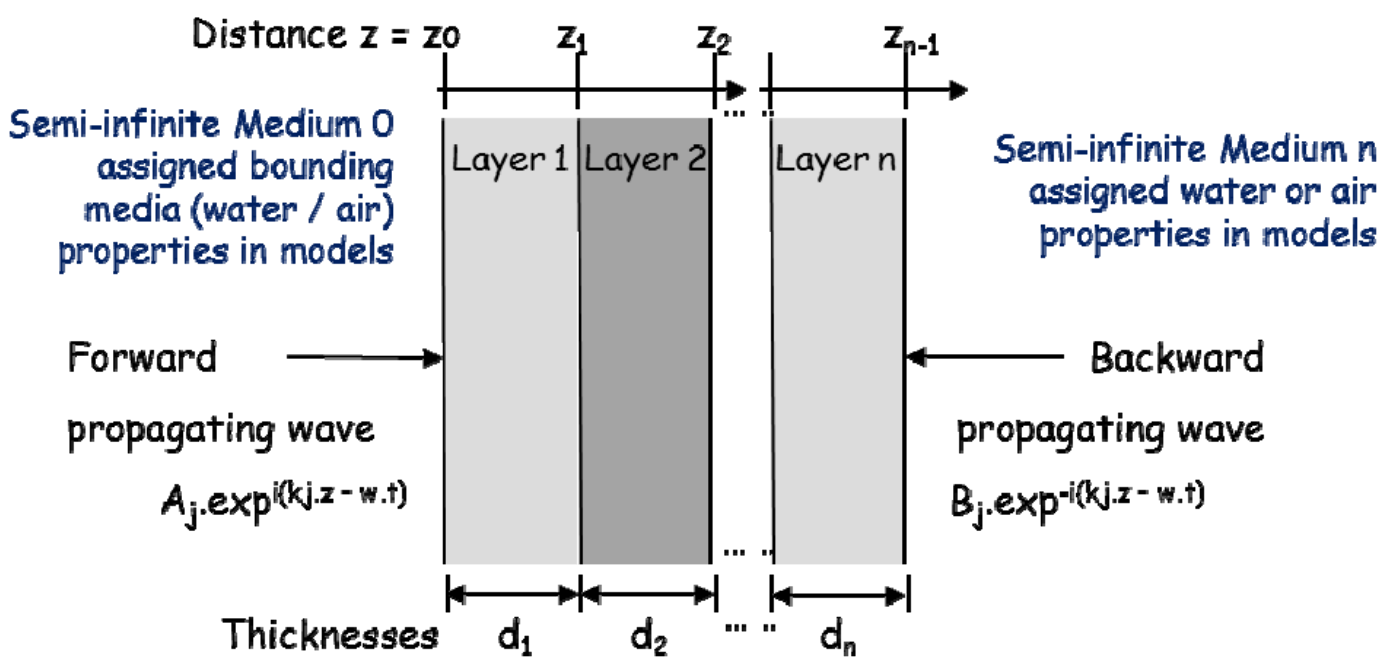

Figure 2. Layout and nomenclature for the numerical process used to model the spectra of the reflection and transmission coefficients for normal incident 1D wave propagation through layered test systems. 


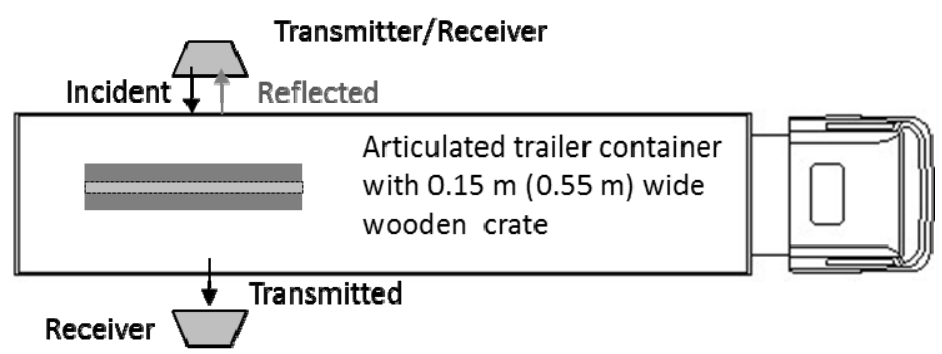

a. Concept based on a linear acoustic tomography system.

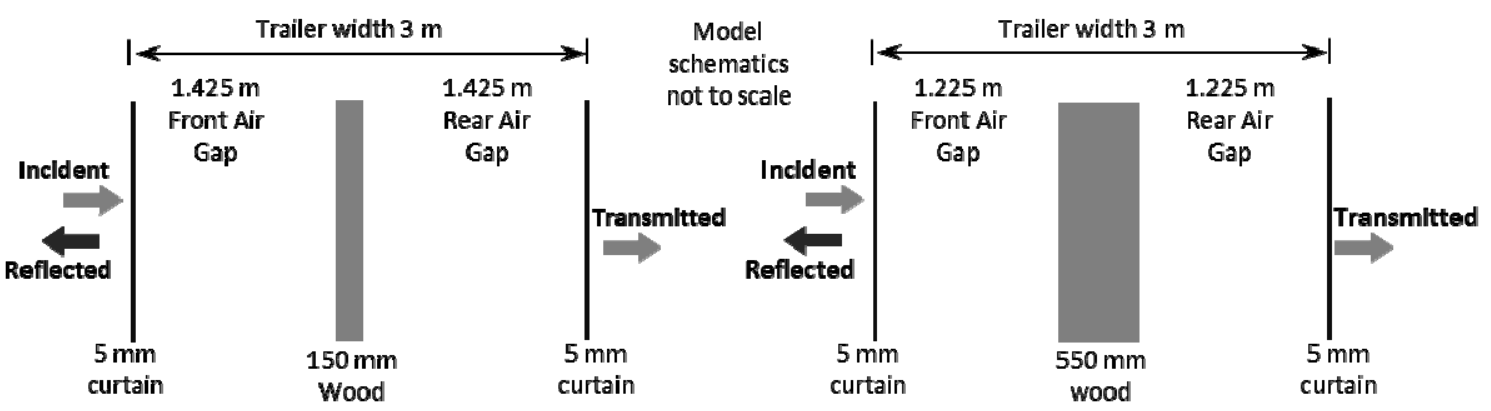

b. Cargo A: $150 \mathrm{~mm}$ solid wooden crate.

c. Cargo B: $500 \mathrm{~mm}$ solid wooden crate.

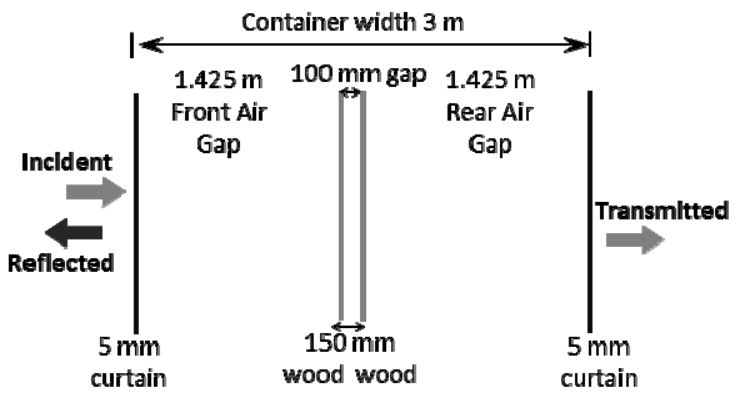

d. Cargo C: $150 \mathrm{~mm}$ empty wooden crate.

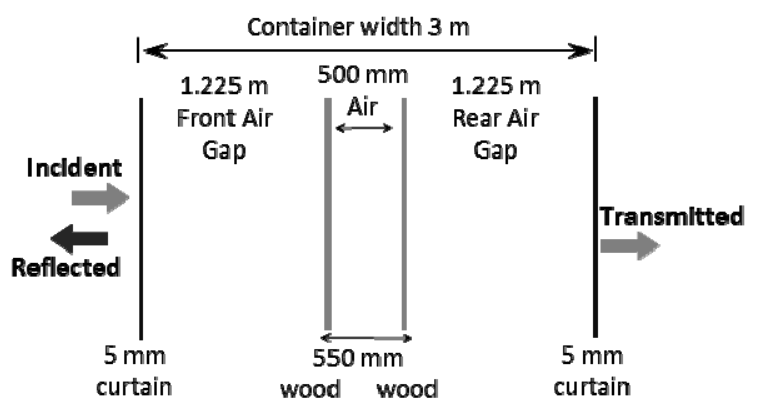

e. Cargo D: $550 \mathrm{~mm}$ empty wooden crate.

Figure 3. Trailer cargo scanner concept: Centrally positioned, variable thickness wooden crates used in modelling examples. 

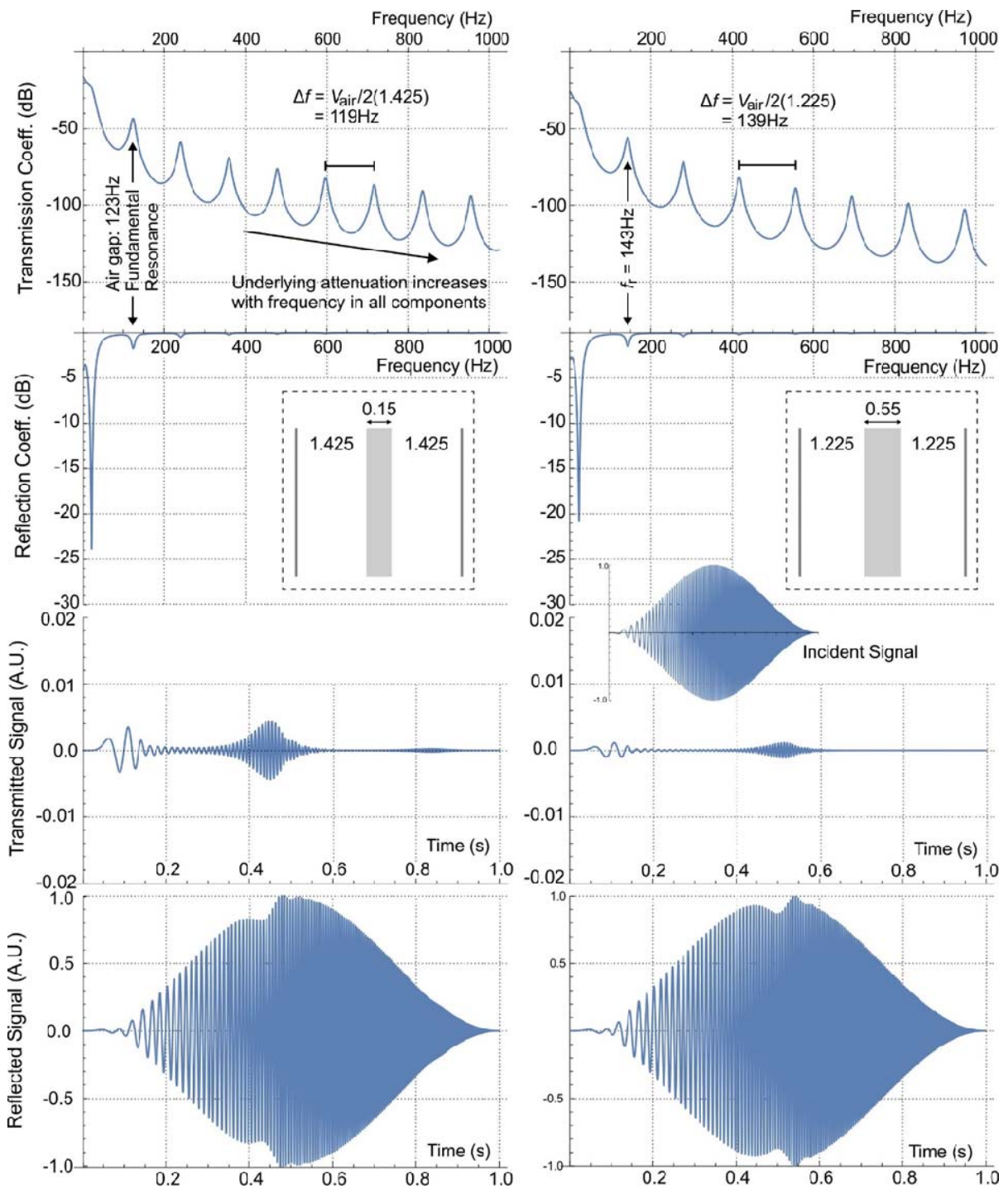

a. Cargo A: $150 \mathrm{~mm}$ solid wooden crate.

b. Cargo B: $550 \mathrm{~mm}$ solid wooden crate.

The spectra of the reflecion and transmissioncoefficients are represented in $\mathrm{dB}$ units. The tempcral signals are rep' esented on a noi rnalised acoustic pressure scale ielative to the incident signal arnplitude.

Figure 4. Trailers with solid wooden crate cargos - centrally positioned: Temporal and spectral characteristics of the transmitted/received signals. 


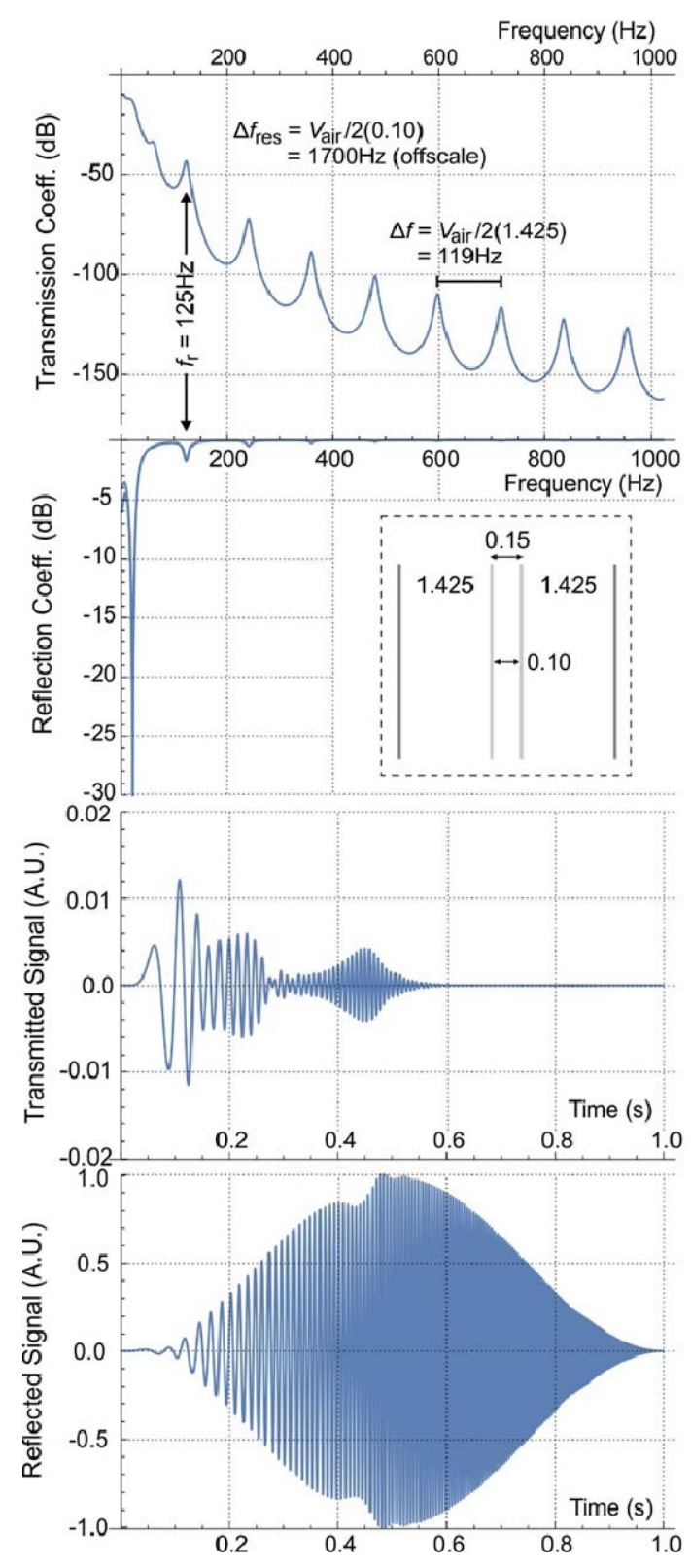

a. Cargo C: $150 \mathrm{~mm}$ empty wooden crate.
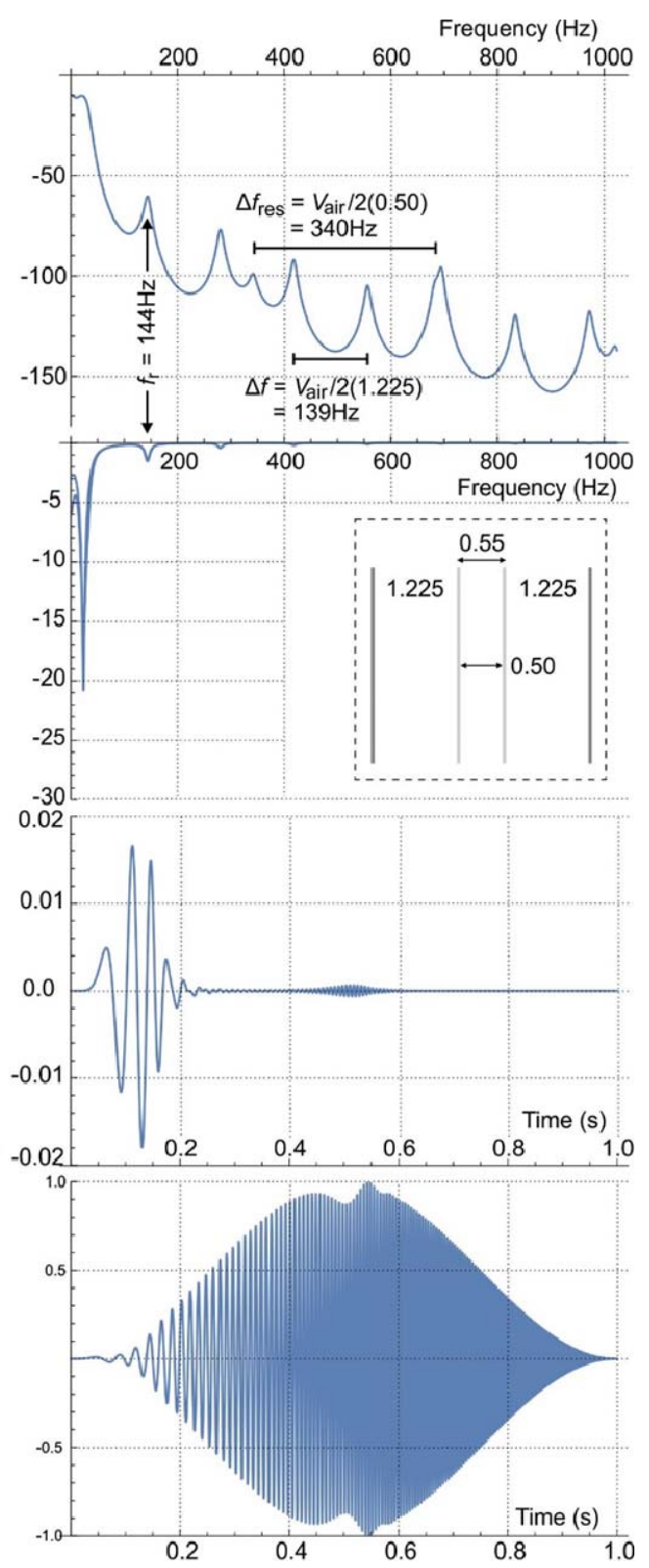

b. Cargo D: $550 \mathrm{~mm}$ empty wooden crate.

Figure 5. Trailers with empty wooden crate cargos - centrally positioned: Temporal and spectral characteristics of the transmitted/received signals. 


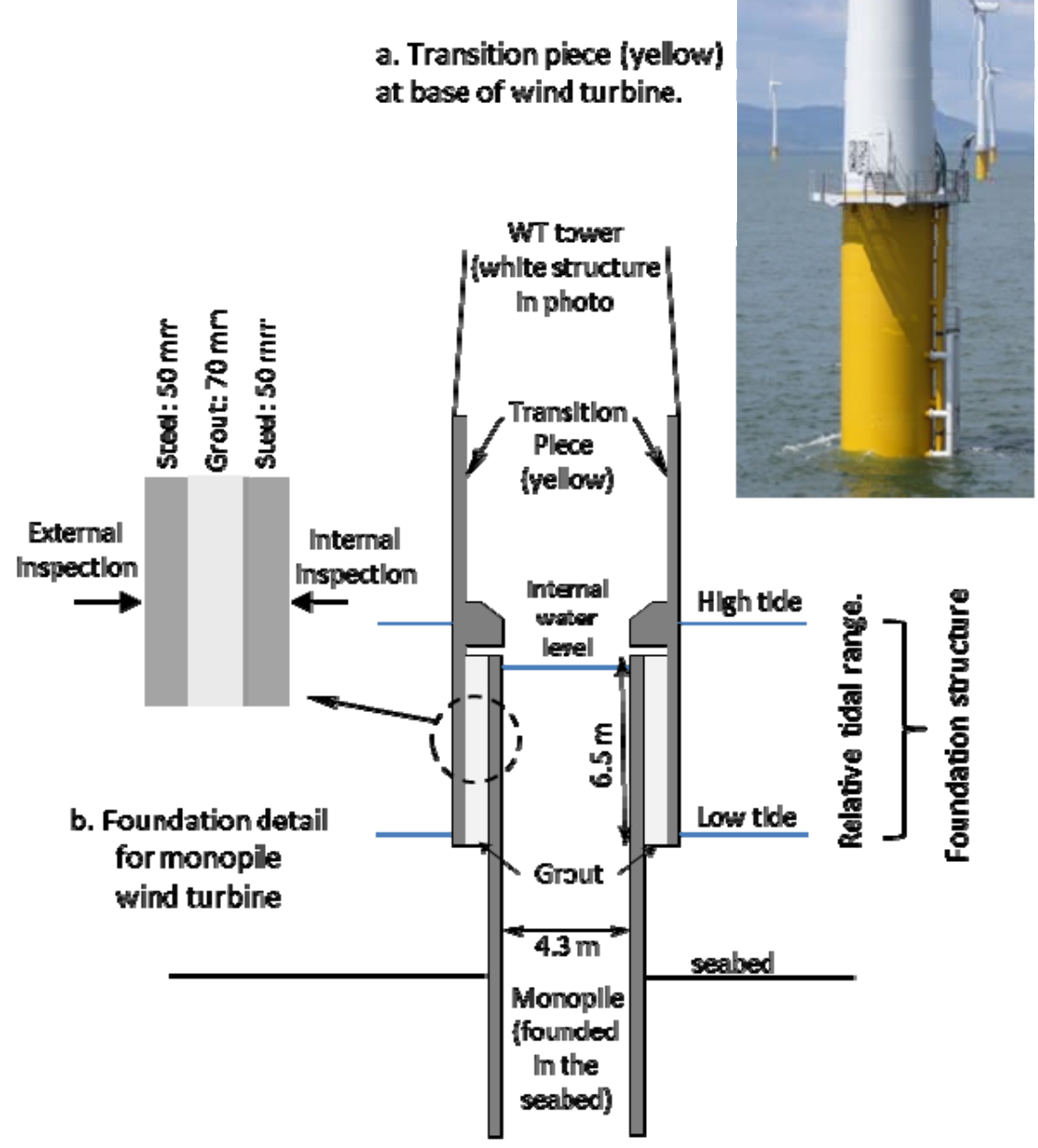

Figure 6. Schematic showing the structural elements and overall dimensions of offshore monople wind turbine foundations. 


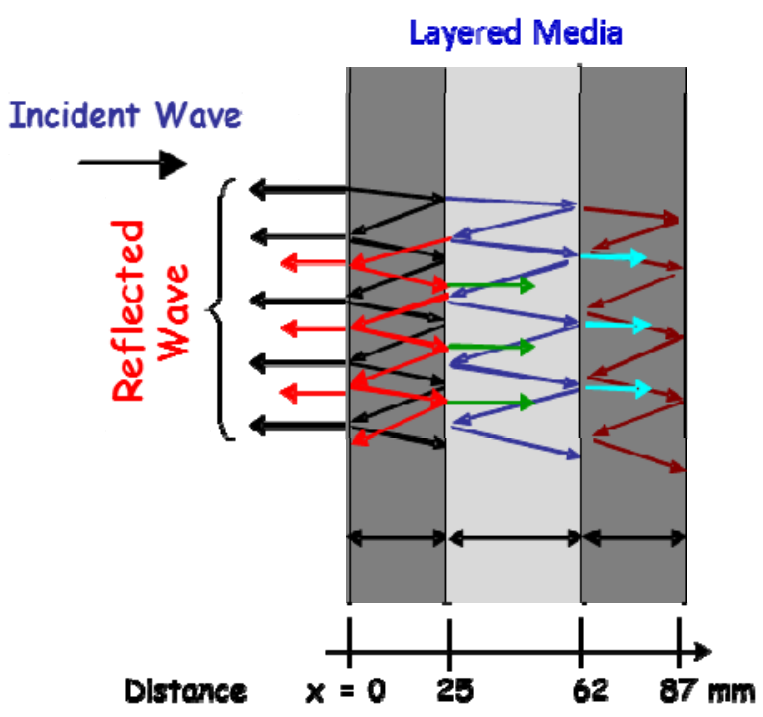

a. Nominal model dimensions, properties and wave propagation modes. OJter layers (dark grey): mild steel $25 \mathrm{mn}, 5918 \mathrm{~m} / \mathrm{s}, 0 \mathrm{~Np} / \mathrm{m}$; Centre (light grey): grout $37 \mathrm{~mm}, 4700 \mathrm{~m} / \mathrm{s}, 10 \mathrm{~Np} / \mathrm{m}$.

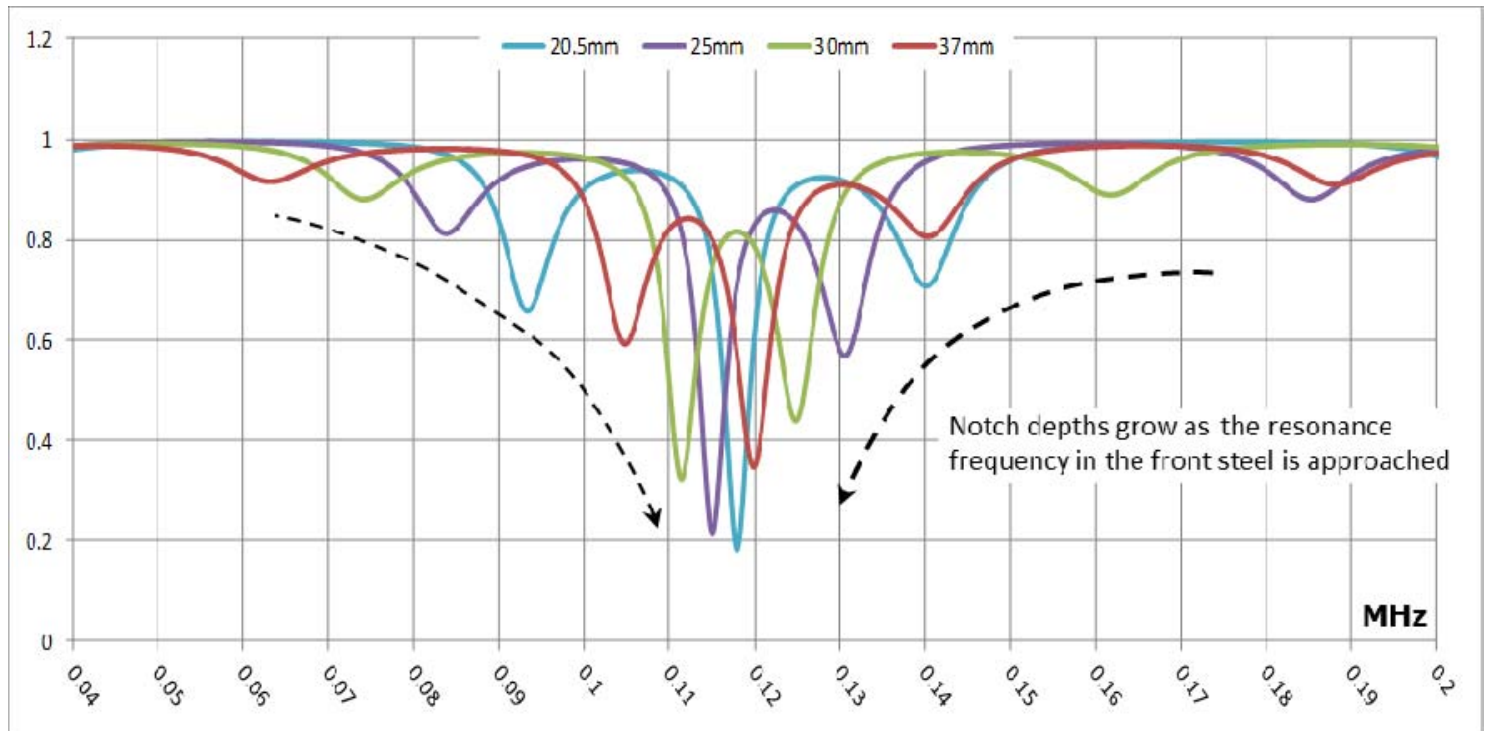

b. Effect of grout thickness on mode outcones: Reflection spectra for $\mathbf{2 0 . 5 - 3 7 ~ m m ~ t h i c k ~ g r o u t . ~}$ Y-AxIs: Reflection Coefficlent; X-Axds: Frequency (MHz)

Figure 7. Reflection spectra for half-thickness scale model of wind turbine monopile foundation structure. 


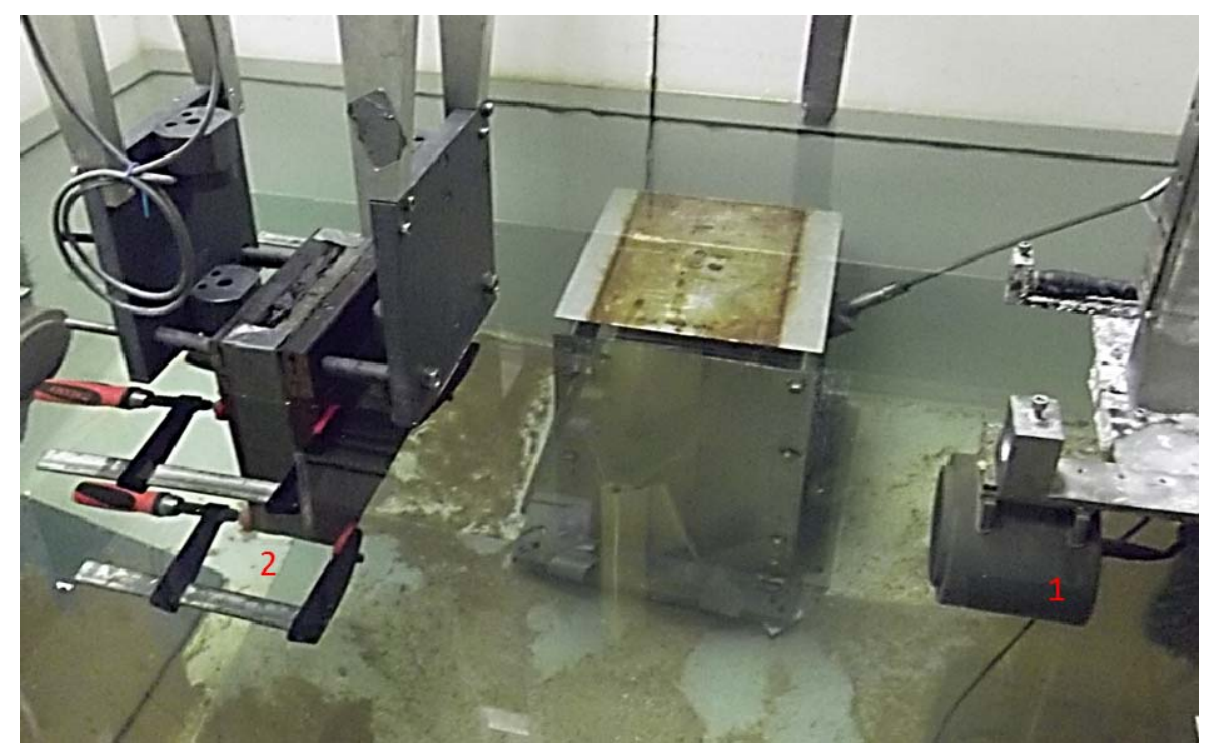

Figure 8. Experimental set-up showing the ultrasound transmitter-receiver (1) and the steelconcrete-steel-sample (2), which is clamped to maintain contact between the concrete and the free steel plate. 


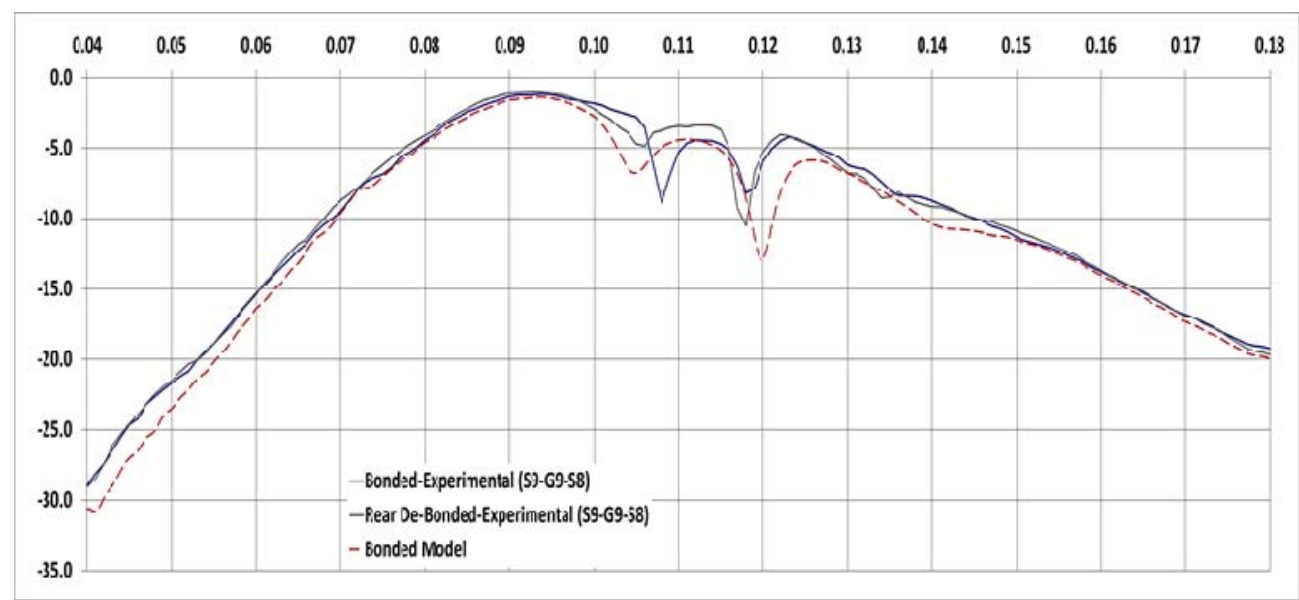

a. Fully bonded steel-grout-steel str.Jcture. Blue solld: Experimental: notches at $108 \mathrm{kHz}$ and $119 \mathrm{kHz}$. Grey Solld: Very loose clamping, effectively relaxing the acoustic oading of the rear stecl-grout interface. Red desh: Modclled: notches at $105 \mathrm{kHz}$ and $120 \mathrm{kHz}$ superimposed onto transducer sensitivity function. Y-axis: $\mathrm{dB}$ (1ormal'sed); $\mathrm{X}$-axis - $\mathrm{MHz}$.

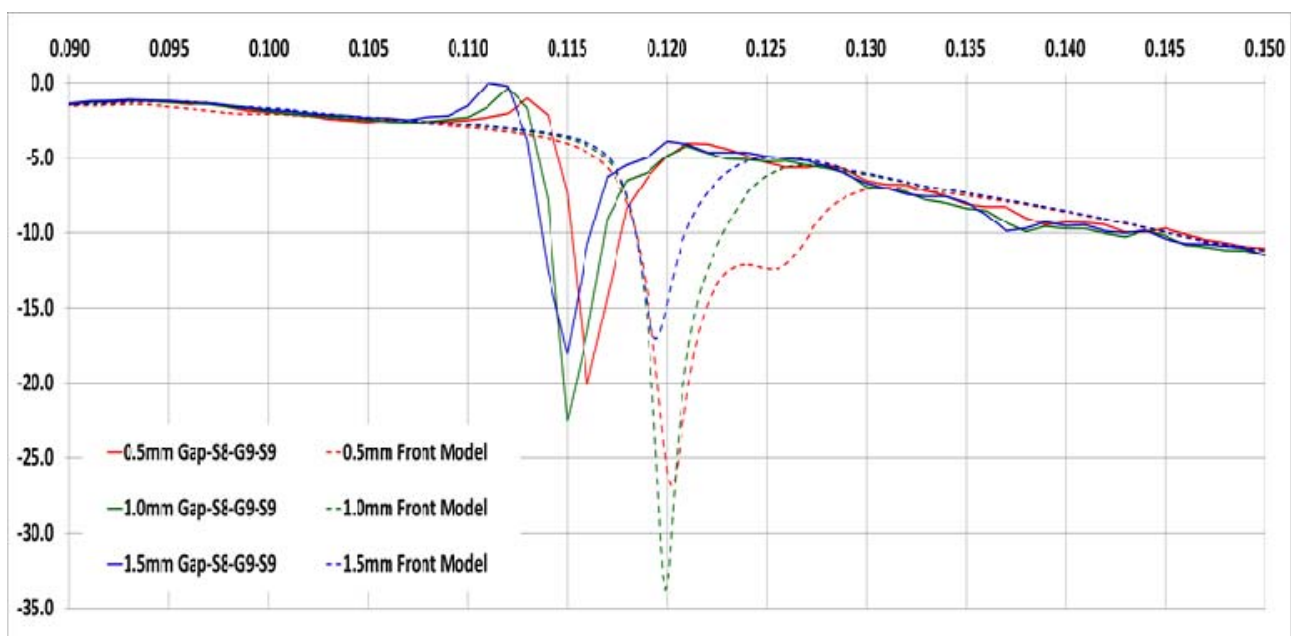

b. Gaps at front stecl-grout interface. Solld Experimental: Gap apertures of $0.5 \mathrm{~mm}$-notch at $116 \mathrm{kr}-$; $1.0 \mathrm{~mm}$ - $115 \mathrm{kH}$; $1.5 \mathrm{mrm}-115 \mathrm{kH}$. Dashed - Mudels: Craces ur 0.5 mrn-rioleh al $120.3 \mathrm{kHz} ; 1.0 \mathrm{~mm}-119.9 \mathrm{kHz} ; 1.5 \mathrm{mn}-119.4 \mathrm{kHz}$. Y-axis: $\mathrm{dB}$ (normalised); X-axis- MHz.

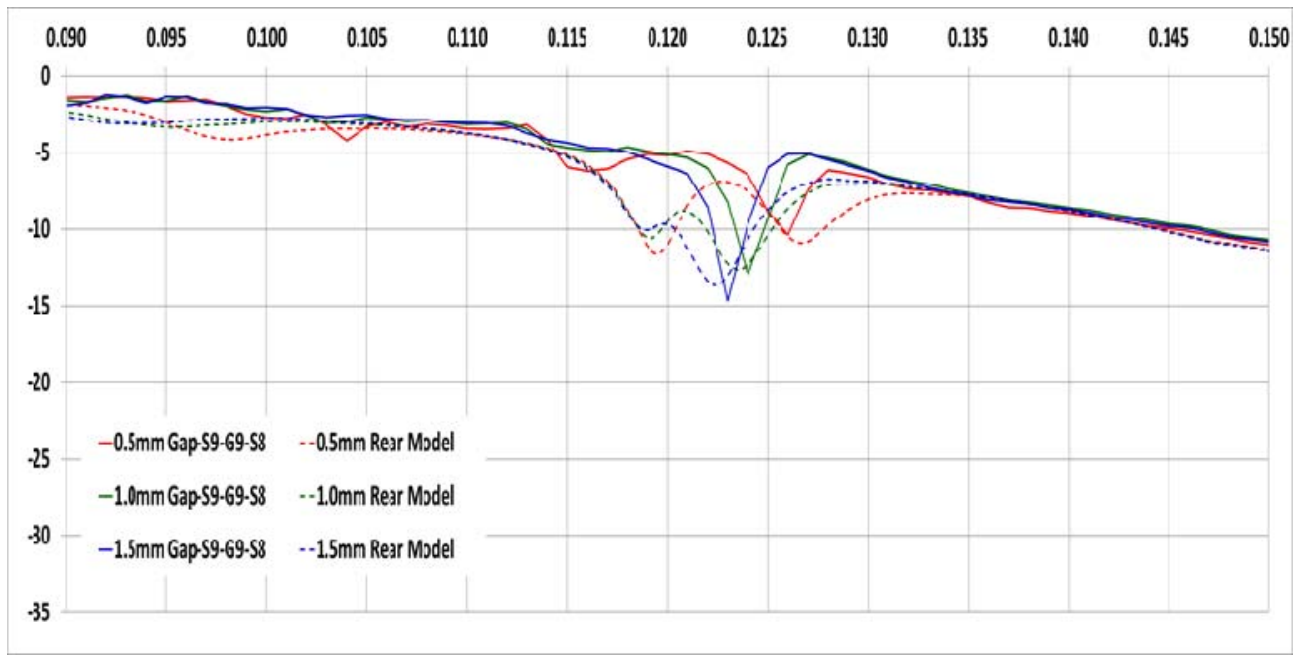

c. Gaps at rear steel-grout interface. Solld - Experimental: Gaps $0.5 \mathrm{~mm}$-notch at $126 \mathrm{kHz} ; 1.0$ mm - 124 kHz; $1.5 \mathrm{~mm}-123 \mathrm{kHz}$. Dashed - Models: Gaps of $0.5 \mathrm{~mm}$-notches $119.5 / 126.8 \mathrm{kHz}$; $1.0 \mathrm{~mm}-119.1 / 123.6 \mathrm{kHz} ; 1.5 \mathrm{~mm}-118.9 / 122.4 \mathrm{kHz}$. Y-axis: $\mathrm{dR}$ (normalised); X-axis - MH7.

Figure 9. Experimental ard modelled reflection spectra for half-thickness scale wind turbine foundatlons with structural defects; front/rear steel $25 \mathrm{~mm}$, central grout $37 \mathrm{~mm}$ thlck. Model parameters: Steel $5918 \mathrm{~m} / \mathrm{s}, 0 \mathrm{~Np} / \mathrm{m}$; Grout $4700 \mathrm{~m} / \mathrm{s}, 10 \mathrm{~Np} / \mathrm{m}$ (frequency independent). 